\title{
Production and mechanical performance of scrimber composite manufactured from poplar wood for structural applications
}

\author{
Min-Juan $\mathrm{He}^{1} \cdot$ Jing Zhang ${ }^{1} \cdot$ Zheng $\mathrm{Li}^{1} \cdot$ Mao-Lin $\mathrm{Li}^{2}$
}

Received: 23 March 2016/Accepted: 3 June 2016/Published online: 15 July 2016

(C) The Japan Wood Research Society 2016

\begin{abstract}
The use of wood-based composite material for structural purposes is of increasing interest. A scrimber composite, which is manufactured from thermally modified fast-growing wood, is introduced in this paper. The production of such scrimber is able to reduce the inherent variability in mechanical properties of natural wood material, and also allows the effective utilization of fastgrowing wood, which is widely available with a low price in China. Experimental tests were conducted to determine the mechanical properties of the scrimber composite. A comparison of mechanical properties of the proposed scrimber composite with other timber/bamboo-based materials is then reported. It is shown that the scrimber composite has desirable mechanical performance as a construction material, which is comparable or superior to those of engineered timber/bamboo products. This study contributes to a potential utilization of fast-growing tree species, and the presented mechanical tests can serve as a fundamental basis for more applications of such composite material in practical engineering.
\end{abstract}

Keywords Scrimber - Laminated composites · Construction material $\cdot$ Mechanical properties . Experimental test

Zheng Li

zhengli@tongji.edu.cn

1 Department of Structural Engineering, Tongji University, Shanghai 200092, China

2 Tianjin Hualin (Group) Co., Ltd., 88 Nanhuan Road, Tianjin 300350, China

\section{Introduction}

Wood is one of the oldest natural building materials in the world. A number of desirable factors, such as simplicity in fabrication, thermal insulation, and environmental compatibility, have made wood one of the most popular construction materials. However, due to stricter environmental regulations and decreasing number of natural forests, fastgrowing wood is expected to be used in building structures because of its ease of reproduction.

Initially, most fast-growing tree species were used to produce pulp and paper due to their low density and poor mechanical properties. However, with increasing demand for wood-based structural materials, many studies have been conducted to investigate the potential and properties of engineered wood products made from fast-growing tree species. Particleboard is a widely used reconstituted wood panel, which does not require high quality raw materials [1]. Previous researches show that density and press time are the main parameters influencing the properties of particleboards made from fastgrowing wood [2-5]. Many fast-growing tree species have been used in the production of laminated veneer lumber (LVL), such as Scots pine (Pinus sylvestris) [6], radiata pine (Pinus radiata) [7], eucalyptus [8], poplar [9, 10], and Gmelina arborea [11]. Previous researches prove that laminated wood possesses superior bending strength and modulus when compared to the same species of solid wood [9]. Using fast-growing tree species in the inner plies of laminated materials can also reduce the producing costs without much decrease in mechanical properties. According to the research by Moya et al. [12], I-beams fabricated from fast-growing wood can be used in roofing and flooring systems. It is also found by researchers that glulam beams made from fast-growing 
wood can be used as structural elements in building constructions [13].

To improve the structural competitiveness of wood products made from fast-growing tree species, several modification processes have been introduced to change its physical and mechanical characteristics. Zephyr strand board and zephyr strand lumber produced from poplar veneer, possess superior mechanical properties to ordinary poplar plywood and LVL [14]. Modifying wood porous structure is quite effective to improve the properties of fastgrowing wood. Wood-polymer composites have been proved to have increased mechanical properties compared to untreated wood [15], and the improved properties of hybrid poplar hardened with methyl methacrylate (MMA) are even comparable to some hardwood species [16].

Scrimber is a reconstituted wood product made from integrated parallel strips, and it always has a comparatively higher raw material utilization rate. Several researches have been conducted to determine the feasibility of manufacturing scrimber from eucalyptus, pinus radiata [17], bamboo [18], and mulberry branches [19], proving that scrimber made from fast-growing species may serve as a promising alternative source for wood products because of its excellent mechanical properties and abundant supply.

In this paper, a veneer-based scrimber composite manufactured from fast-growing wood is introduced. The wood species used is poplar, which is extensively planted in China [20]. This paper introduces the production of the scrimber composite, investigates its main mechanical properties by experimental tests and provides a comparison between such scrimber and other timber/bamboo-based materials.

\section{Materials and methods}

\section{Scrimber manufacturing}

The manufacturing method to produce scrimber composite from low-quality and fast-growing poplar is presented in Fig. 1. The producing process has six main steps consisting of mechanical slicing, drying, thermal treatment, impregnation, cold molding, and hot curing. Several industrial equipments, such as wood veneer lathe, veneer dryer, modification tank, cold-press mold, and hot curing chamber have been used. The detailed producing steps are listed as follows:

1. Natural poplar logs are first sliced circumferentially to form veneers with a thickness of about $2 \mathrm{~mm}$. The uniformity of veneer lumber is quite important for physical and mechanical properties of the scrimber composite.
2. The veneers are dried in a kiln to approximately $20 \%$ moisture content and treated by modifiers to achieve mold proof and fire retardant properties. This treatment can contribute to a good dimensional stability and durability of the product.

3. The modified veneers are saturated in resin and dried again after saturation. The veneers are stored to keep the moisture content of around $20 \%$.

4. Cold molding, hot curing and hot pressing are included in the forming process. Laminate the veneers with their original size and coil the veneers into a rectangular cross section. After cold molding and hot curing, compress the scrimber composite in two orthogonal directions on the cross section plane, and thus cross section featured by curved thin laminates can be observed, which is quite different from existing veneer-based laminated products, as shown in Fig. 2. The density of the scrimber composite is increased to $780-940 \mathrm{~kg} / \mathrm{m}^{3}$, and the surface appearance of the composite can be improved as well.

\section{Mechanical properties}

The scrimber composite has an average density of $885 \mathrm{~kg} /$ $\mathrm{m}^{3}$. Before testing, all specimens are conditioned in a climate room for 2 weeks at a constant temperature of $20{ }^{\circ} \mathrm{C}$ and a relative humidity of $60 \%$, and the average moisture content of the specimens is $18 \%$.

The following mechanical properties of the scrimber composite were tested: (1) compressive strength (parallel and perpendicular to the grain), (2) tensile strength (parallel and perpendicular to the grain), (3) shear strength, (4) static bending strength, (5) bending modulus.

\section{Compression test parallel to the grain}

Parallel-to-grain compression test was conducted according to Chinese standard GB/T 1935-2009 [21]. Sixty specimens with the size of $20 \times 20 \times 80 \mathrm{~mm}$ (tangential $\times$ radial $\times$ longitudinal) were prepared. The experiment was conducted on a universal testing machine with an ultimate capacity of $50 \mathrm{kN}$. Compressive load was applied continuously at a rate of $0.5 \mathrm{~mm} / \mathrm{min}$. The test setup is shown in Fig. 3. The modulus of elasticity and compressive strength were calculated by:

$E_{\|}^{\mathrm{c}}=\frac{\Delta F_{\|}^{\mathrm{c}}}{w d \Delta \varepsilon_{\|}^{\mathrm{c}}}, f_{\|}^{\mathrm{c}}=\frac{F_{\|}^{\mathrm{cp}}}{w d}$

where $\Delta F_{\|}^{\mathrm{c}}$ and $\Delta \varepsilon_{\|}^{\mathrm{c}}$ are compressive load increment and strain increment along the longitudinal direction within the linear elastic loading stage, respectively; $F_{\|}^{\mathrm{cp}}$ is the ultimate compressive load applied on the specimens; $w$ and $d$ are the 

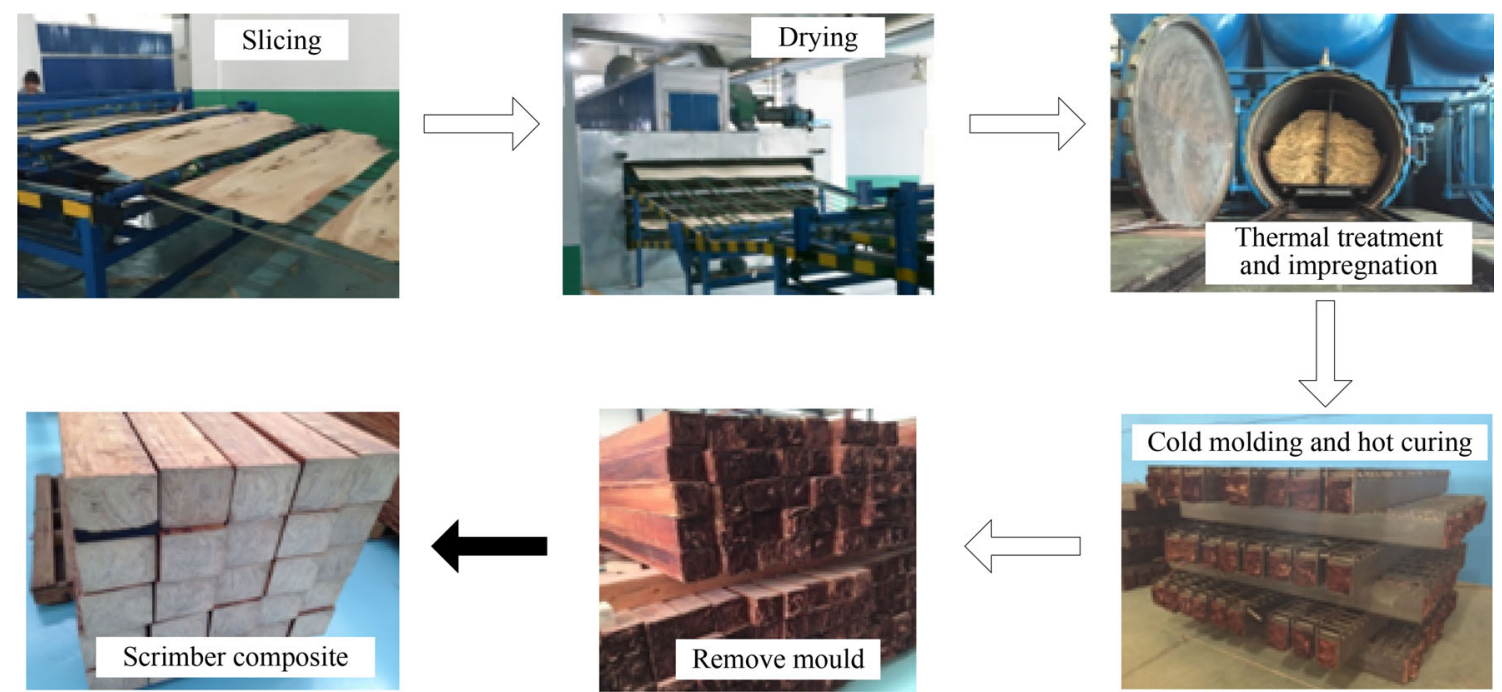

Fig. 1 Production of the scrimber composite



Fig. 2 Cross section of the scrimber composite



Fig. 3 Setup of compression test parallel to the grain

actually measured cross sectional dimensions of the specimens. The average compressive strength parallel to the grain is obtained as $101 \mathrm{MPa}$, and the modulus of elasticity is obtained as $16,780 \mathrm{MPa}$. The variation coefficients for compressive strength and modulus of elasticity are 9.9 and $13.3 \%$, respectively.

A typical stress-strain curve and three main failure modes of the scrimber composite are shown in Fig. 4. The proportional limit corresponds to the maximum stress in the linear segment of the strain-stress curve, as shown in Fig. 4a. With the applied load increasing beyond the proportional limit, primary crack was observed and the crack gradually extended along the longitudinal direction. Crushing failure was observed when the specimen reached the ultimate load-carrying capacity, as shown in Fig. 4b. It was found that wood pieces were separated from each other along the glue layer in a few specimens, corresponding to their ultimate limit state, as shown in Fig. 4c. Some specimens were divided into several sub-columns by cracks, and buckling failure was observed in the sub-columns, as shown in Fig. 4d. Moreover, a secondary inelastic behavior can be observed in the stress-strain curve, which indicates a ductile post-yielding behavior.

\section{Compression test perpendicular to the grain}

Perpendicular-to-grain compression test was conducted according to Chinese standard GB/T 1939-2009 [22]. Sixty specimens with the size of $25 \times 25 \times 100 \mathrm{~mm}$ were prepared for the test. Thirty specimens were loaded in the radial direction and the others were loaded in the tangential direction. Compressive load was applied monotonically at a rate of $0.5 \mathrm{~mm} / \mathrm{min}$. The test setup is presented in Fig. 5 . The modulus of elasticity and compressive strength were obtained by:

$E_{\perp}^{\mathrm{c}}=\frac{\Delta F_{\perp}^{\mathrm{c}}}{w d \Delta \varepsilon_{\perp}^{\mathrm{c}}}, f_{\perp}^{\mathrm{c}}=\frac{F_{\perp}^{\mathrm{cp}}}{w d}$ 
Fig. 4 Parallel-to-grain compressive test results: a typical stress-strain curve; b crushing failure with crack propagation along the grain direction; $\mathbf{c}$ failure with wood pieces separated along the glue layer; $\mathbf{d}$ buckling failure in subcolumns


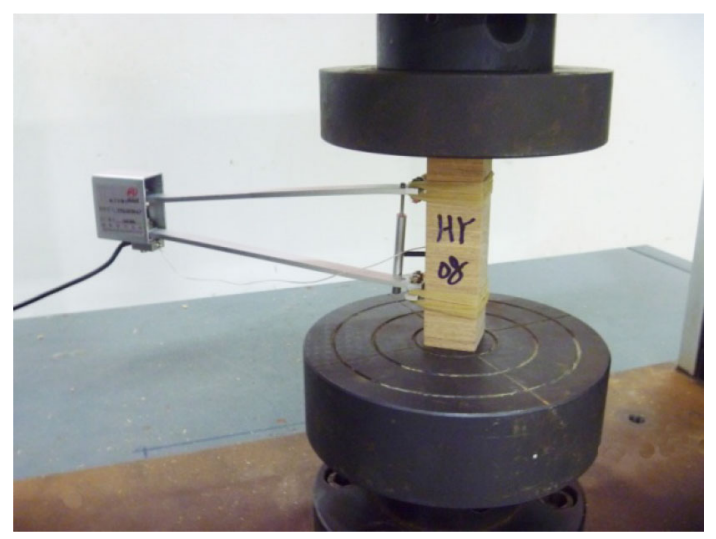

Fig. 5 Setup of compression test perpendicular to the grain

where $\Delta F_{\perp}^{\mathrm{c}}$ and $\Delta \varepsilon_{\perp}^{\mathrm{c}}$ are the compressive force increment and its corresponding strain increment perpendicular to the grain within the linear elastic loading stage, respectively; $F_{\perp}^{\mathrm{cp}}$ is the peak force applied on the specimens; $w$ and $d$ are the actually measured cross sectional dimensions of the specimens. The average compressive strength perpendicular to the grain is obtained as $21 \mathrm{MPa}$, and the modulus of elasticity is obtained as $1242 \mathrm{MPa}$. The variation coefficients for compressive strength and modulus of elasticity are 14.3 and $8.5 \%$, respectively.

The typical stress-strain curve and failure modes of the scrimber composite under compressive force perpendicular to the grain are shown in Fig. 6. An initial linear elastic range can be observed in the stress-strain curve, and the proportional limit in the radial direction is much lower than that in the tangential direction, as shown in Fig. 6a. For the specimens loaded in the tangential direction, a crack along the glue layer was observed beyond the proportional limit, and the crack gradually propagated along the glue line with the increasing compressive force, as shown in Fig. 6 b. However, for specimens loaded in the radial direction, a crack slope to the loading direction was found, and finally, a slipping shear surface was formed, as shown in Fig. 6c. Both the compressive strength and modulus in the radial direction are lower than those in the tangential direction, as listed in Table 1. 


\section{Tension test parallel to the grain}

The geometric configuration of the specimens for parallelto-grain tensile test, which was designed according to Chinese standard (GB/T 1938-2009 [23]), is shown in Fig. 7. Sixty specimens were prepared for the tension test. A pair of grips was used to hold the specimens and the


Fig. 6 Perpendicular-to-grain compressive test results: a typical stress-strain curve for tangential and radial directions; $\mathbf{b}$ failure with crack propagation along glue line for tangential specimens; $\mathbf{c}$ crushing failure with a diagonal crack for radial specimens tensile strain along the grain was measured by an electronic extensometer, which was installed in the middle part of the specimens. The tensile load was applied continuously at a rate of $1 \mathrm{~mm} / \mathrm{min}$. The modulus of elasticity and tensile strength were obtained by:

$E_{\|}^{\mathrm{t}}=\frac{\Delta F_{\|}^{\mathrm{t}}}{b t \Delta \varepsilon_{\|}^{\mathrm{t}}}, f_{\|}^{\mathrm{t}}=\frac{F_{\|}^{\mathrm{tu}}}{b t}$

where $\Delta F_{\|}^{\mathrm{t}}$ and $\Delta \varepsilon_{\|}^{\mathrm{t}}$ are the tensile force increment and its corresponding strain increment parallel to the grain within the linear elastic loading range, respectively; $F_{\|}^{\mathrm{tu}}$ is the peak tensile load applied on the specimens; $b$ and $t$ are the actually measured dimensions at the critical cross section of the specimens. The average tensile strength parallel to the grain is obtained as $108 \mathrm{MPa}$, and the modulus of elasticity is obtained as $11,069 \mathrm{MPa}$. The variation coefficients for tensile strength and modulus of elasticity are 23.1 and $6.6 \%$, respectively.

Figure 8 shows a typical stress-strain curve and failure modes of the scrimber composite under tension parallel to the grain. The scrimber composite exhibits a bilinear behavior prior to failure, as shown in Fig. 8a. Rupture failure was observed in the center part of most specimens followed by a sudden loss of the load-carrying capacity. Flat and diagonal fracture surfaces appeared in the middle part of the specimens, as shown in Fig. 8b, c, respectively. Rupture failure with a crack propagating along the grain direction was also observed in several specimens, as shown in Fig. 8d. It should be noted that no significant difference of test results was found among these three failure modes.

\section{Tension test perpendicular to the grain}

The geometric configuration of the specimens for perpendicular-to-grain tensile test is shown in Fig. 9. The specimens were designed according to ASTM D143-14 [24]. Thirty specimens were loaded in the radial direction, and
Table 1 Mechanical properties for the scrimber composite

\begin{tabular}{|c|c|c|c|c|c|c|}
\hline \multirow[t]{2}{*}{ Category } & \multirow[t]{2}{*}{ Direction of loading } & \multicolumn{3}{|c|}{ Strength $(\mathrm{MPa})$} & \multicolumn{2}{|c|}{$\operatorname{MOE}(\mathrm{MPa})$} \\
\hline & & Mean & $\operatorname{COV}(\%)$ & 5 -percentile & Mean & $\operatorname{COV}(\%)$ \\
\hline \multirow[t]{3}{*}{ Compression } & Parallel-to-grain & 101 & 9.9 & 84.3 & 16,780 & 13.3 \\
\hline & Perpendicular-to-grain radial & 18 & 10.1 & 15.2 & 1167 & 7.1 \\
\hline & Perpendicular-to-grain tangential & 24 & 6.2 & 21.7 & 1317 & 5.2 \\
\hline \multirow[t]{3}{*}{ Tension } & Parallel-to-grain & 108 & 23.1 & 64.4 & 11,069 & 6.6 \\
\hline & Perpendicular-to-grain radial & 2 & 22.0 & 1.4 & - & - \\
\hline & Perpendicular-to-grain tangential & 4 & 21.2 & 2.8 & - & - \\
\hline Shear & Parallel-to-grain & 17 & 13.0 & 13.7 & - & - \\
\hline Flexural & - & 140 & 12.1 & 113.4 & 22,310 & 9.4 \\
\hline
\end{tabular}

$C O V$ coefficient of variation, $M O E$ modulus of elasticity 
Fig. 7 Test setup and specimen geometry of tension test parallel to the grain
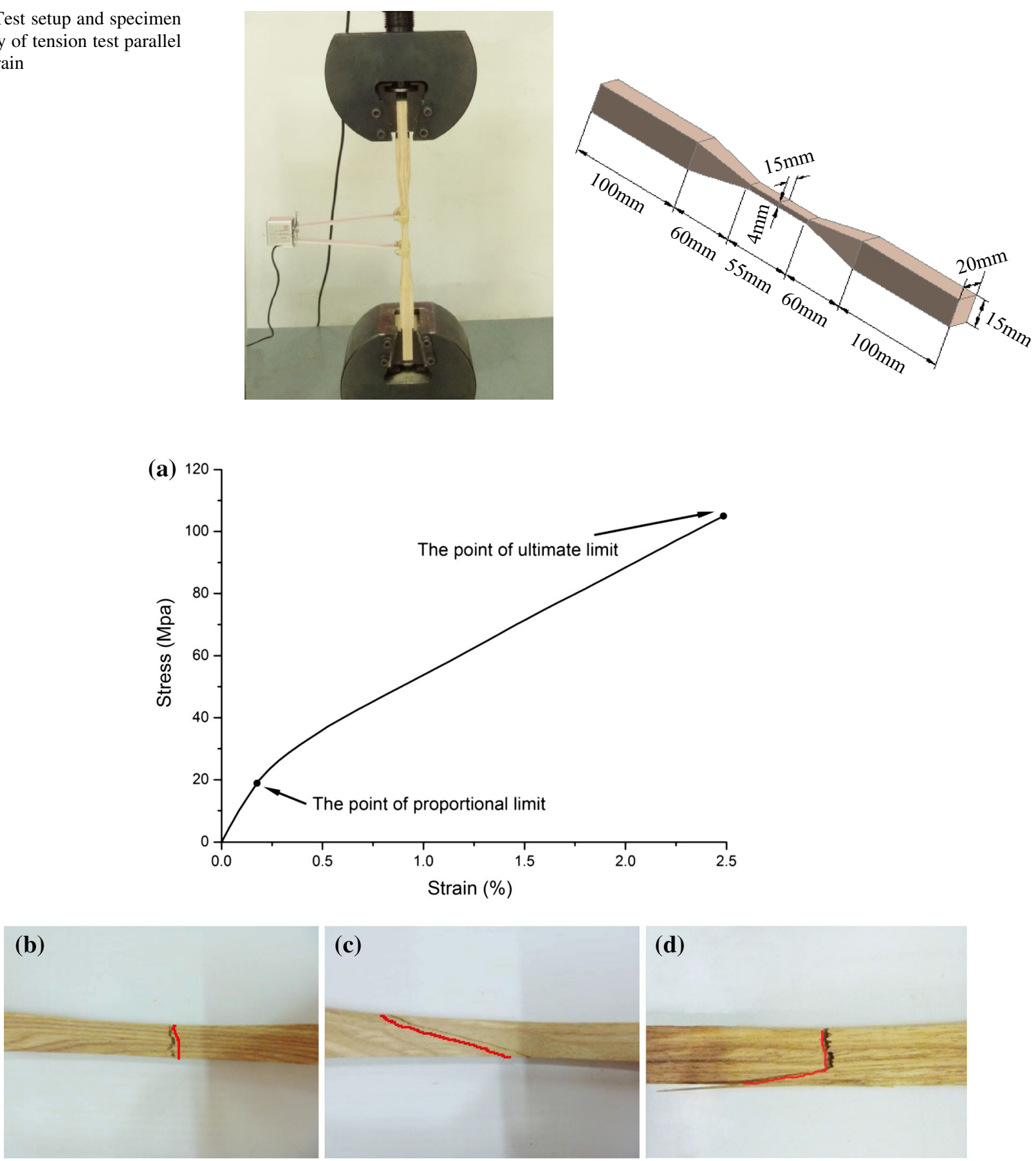

Fig. 8 Parallel-to-grain tensile test results: a typical stress-strain curve; b rupture failure at center part with a flat fracture surface; $\mathbf{c}$ rupture failure at center part with a diagonal fracture surface; $\mathbf{d}$ rupture failure with crack propagation along the grain direction

the others were loaded in the tangential direction. Tensile load was applied continuously at a rate of $0.5 \mathrm{~mm} / \mathrm{min}$. The test setup is presented in Fig. 9. The modulus of elasticity and tensile strength were obtained by:

$E_{\perp}^{\mathrm{t}}=\frac{\Delta F_{\perp}^{\mathrm{t}}}{b t \Delta \varepsilon_{\perp}^{\mathrm{t}}}, f_{\perp}^{\mathrm{t}}=\frac{F_{\perp}^{\mathrm{tu}}}{b t}$ where $\Delta F_{\perp}^{\mathrm{t}}$ and $\Delta \varepsilon_{\perp}^{\mathrm{t}}$ are the tensile force increment and its corresponding strain increment perpendicular to the grain within the linear elastic loading range, respectively; $F_{\perp}^{\mathrm{tu}}$ is the ultimate tensile load applied on the specimen; $b$ and $t$ are the actually measured dimensions at the critical cross section of the specimens. The average tensile strength 
Fig. 9 Test setup and specimen geometry of tension test perpendicular to the grain
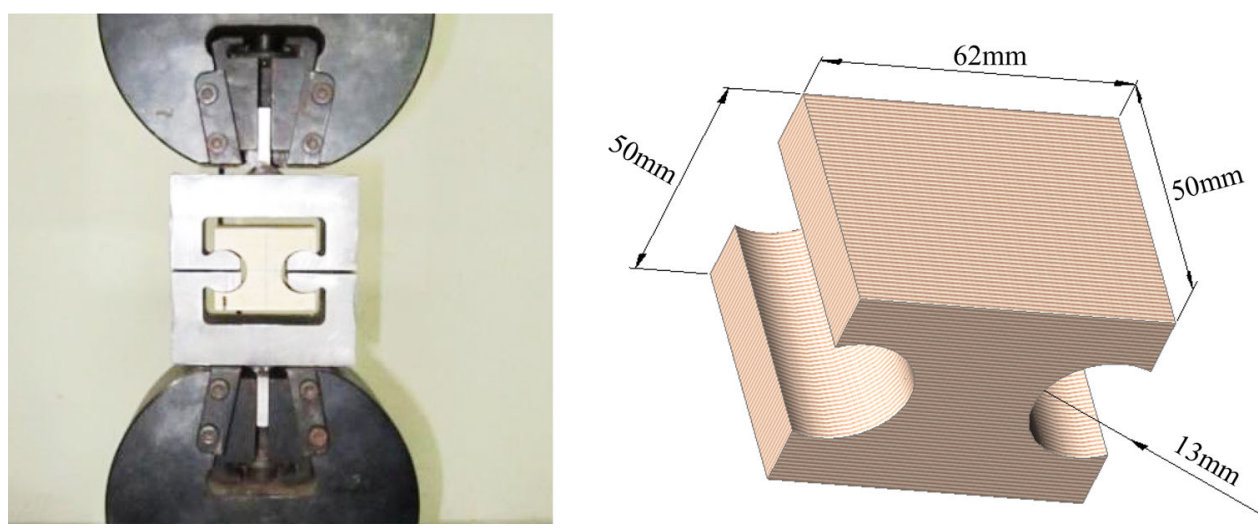

Fig. 10 Perpendicular-to-grain tensile test results: a typical stress-displacement curve for tangential and radial specimens; b failure with crack propagation along the grain direction; c transverse tensile failure for tangential specimens; $\mathbf{d}$ failure with separation near the center part along glue layer
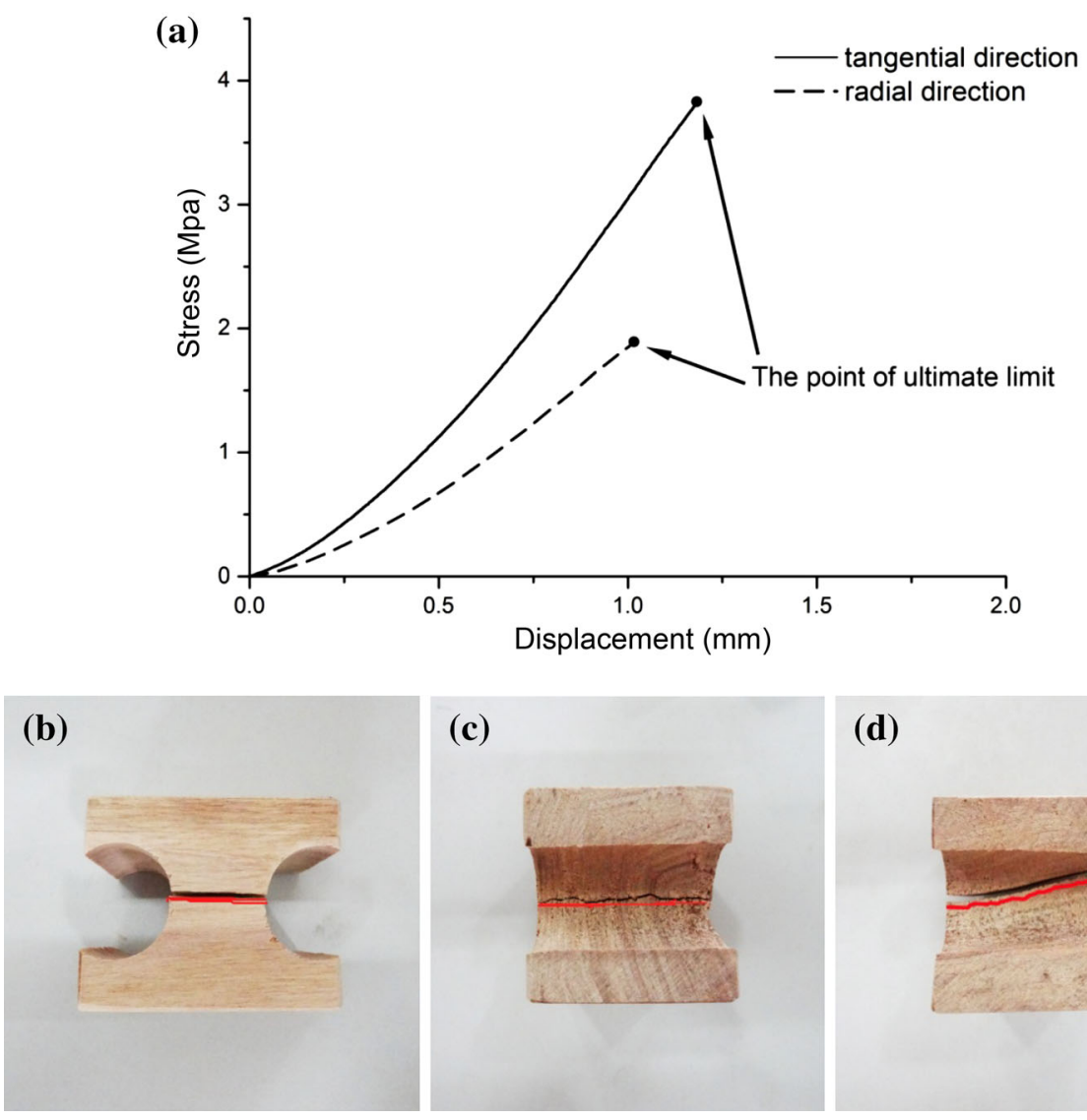

(c)

(d) perpendicular to the grain is obtained as $3.4 \mathrm{MPa}$ with a variation coefficient of $25.2 \%$.

Figure 10 presents a typical stress-displacement relationship and failure modes of the scrimber composite under tensile force perpendicular to the grain. The slope of stressdisplacement curve increases gradually and then goes into a linear segment, as shown in Fig. 10a. For specimens under tension in the tangential direction, failure is featured by a running through crack along the grain direction, as shown in Fig. 10b, c. However, for specimens loaded in the radial direction, tensile failure occurred near the center part through the glue layer, as shown in Fig. 10d. The obtained tensile strength in the radial direction is lower than that in the tangential direction, as listed in Table 1.

\section{Shear test}

Shear test was conducted according to Chinese standard GB/T 1937-2009 [25]. The geometric configuration of the specimens for shear test is shown in Fig. 11. The specimens were divided into two groups. Thirty specimens were machined for shear test along the tangential-longitudinal 
Fig. 11 Test setup and specimen geometry for shear test


(a)

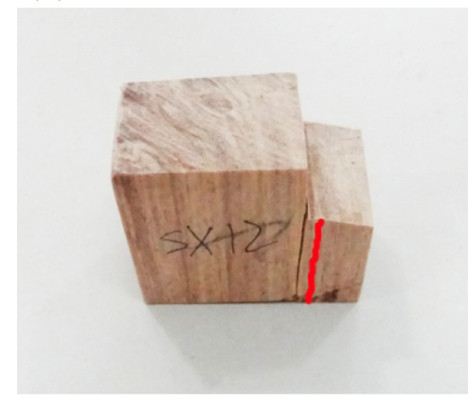

(b)

(c)

Fig. 12 Shear test results: a failure mode of tangential-longitudinal shear plane; b failure mode of radial-longitudinal shear plane; $\mathbf{c}$ observed failure surface after shear test

shear plane, and the other thirty specimens were machined for shear test along the radial-longitudinal shear plane. The loading rate was set at $0.6 \mathrm{~mm} / \mathrm{min}$. The shear strength was obtained by:

$f_{\|}^{\mathrm{s}}=\frac{0.96 F_{\|}^{\mathrm{su}}}{b l}$

where $F_{\|}^{\mathrm{su}}$ is the peak shearing load applied on the specimens; $b$ and $l$ are the actually measured bidirectional dimensions of the shear plane. The average shear strength is obtained as $17 \mathrm{MPa}$ with a variation coefficient of $13.0 \%$.

The failure mode was almost the same among all the specimens, as shown in Fig. 12. Cracks always extended along the grain direction, and consequently, the specimens were separated into two parts along the shear plane, as shown in Fig. 12a, b. Rough failure surface was observed after shear test, as shown in Fig. 12c.

\section{Bending strength test}

Bending strength test was conducted according to Chinese standard GB/T 1936.1-2009 [26]. Thirty specimens with the dimension of $20 \times 20 \times 300 \mathrm{~mm}$ were prepared. The longitudinal direction of the specimens is along the grain direction. The bending strength test was conducted with a point load applied in the middle of the specimens, as shown in Fig. 13. The loading rate was set at $3.5 \mathrm{~mm} / \mathrm{min}$. The bending strength was calculated by:

$f^{\mathrm{b}}=\frac{3 F^{\mathrm{bu}} l}{2 b h^{2}}$

where $F^{\text {bu }}$ is the peak load corresponding to the ultimate load-carrying capacity of the specimens; $l$ is the span length between the two supports; $b$ and $h$ are the actually measured cross sectional dimensions of the specimens. The average bending strength is obtained as $140 \mathrm{MPa}$ with a variation coefficient of $12.1 \%$.

A typical load-deflection curve and the failure mode of bending specimens are shown in Fig. 14. The bending behavior exhibits a clear linear elastic range initially and then the slope of load-deflection curve decreases gradually with tension failure of the bottom veneers, as shown in Fig. 14a. On further loading, more sheets failed in tension and the crack began to extend along the grain up to the maximum load-carrying capacity, as shown in Fig. 14b. 
Fig. 13 Test setup and specimen dimension of static bending strength test
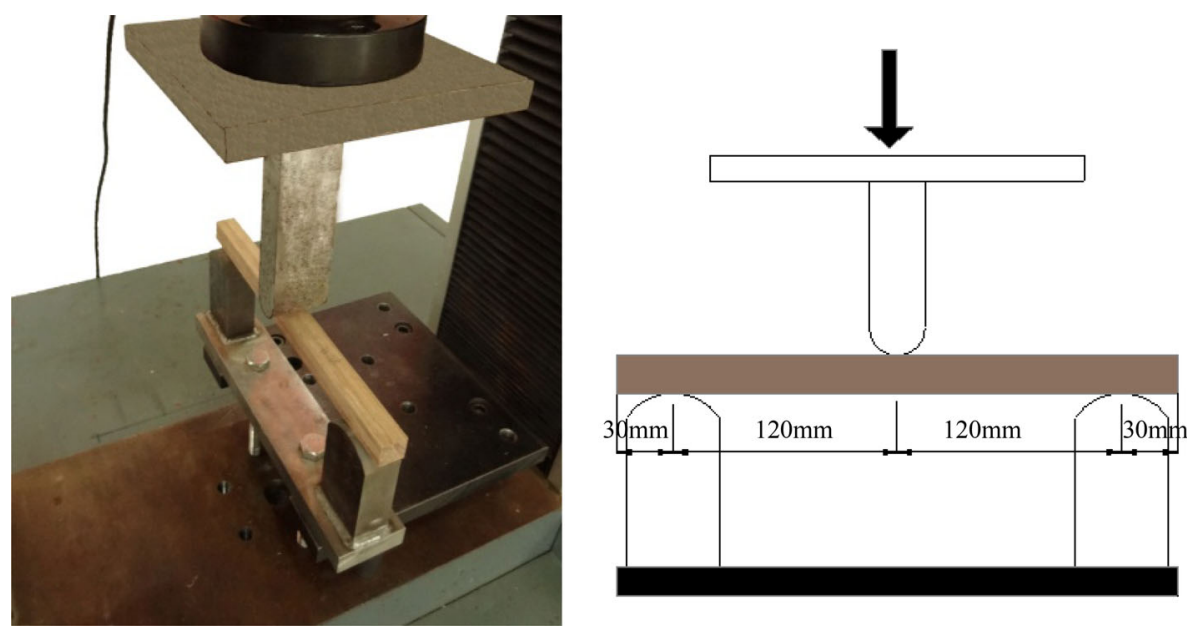

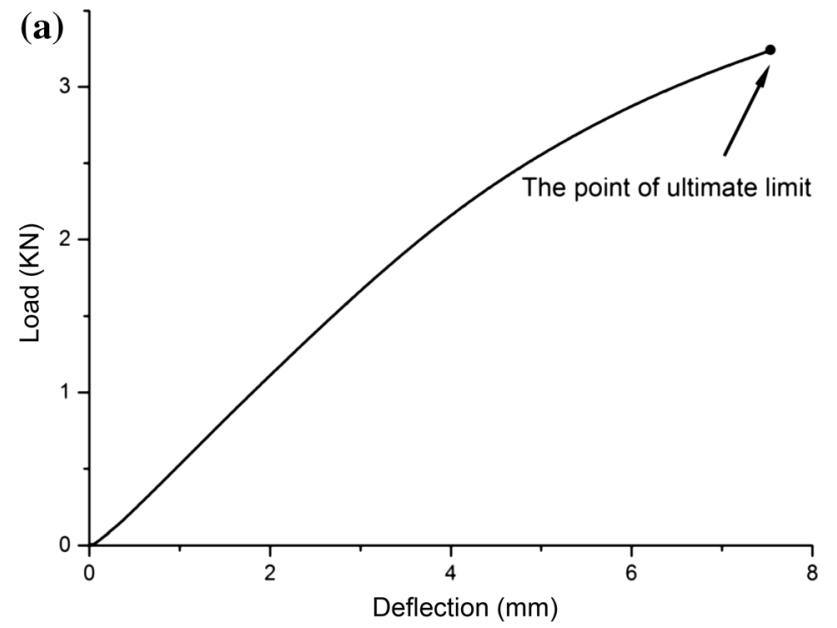

(b)

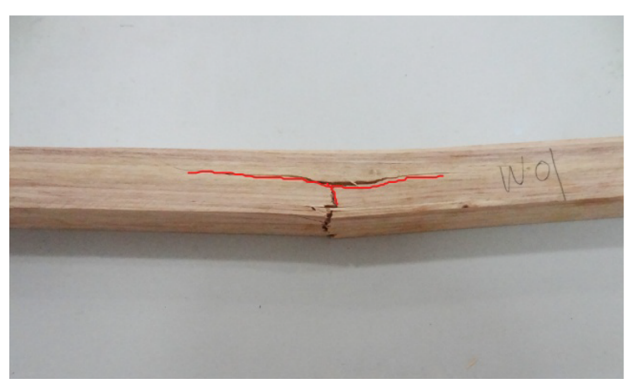

Fig. 14 Static bending test results: a typical load-deflection curve; b failure at the mid-span

\section{Bending modulus test}

Bending modulus test was conducted according to Chinese standard GB/T 1936.2-2009 [27]. Thirty specimens with the dimension of $20 \times 20 \times 300 \mathrm{~mm}$ were prepared. The test setup is shown in Fig. 15. All the specimens for bending modulus test were loaded at two points with a distance of $80 \mathrm{~mm}$. The load was applied continuously up to the upper limit (i.e., $40 \%$ of the ultimate load-carrying capacity of the specimen) at a rate of $1.5 \mathrm{~mm} / \mathrm{min}$ and then unloaded to the lower limit (i.e., $10 \%$ of the ultimate loadcarrying capacity of the specimen) with the same rate. The loading and unloading processes were repeated for four times. The bending modulus was calculated by:

$E^{\mathrm{b}}=\frac{23 P l^{3}}{108 b h^{3} f}$

where $P=P_{\text {upper }}-P_{\text {lower }}, P_{\text {upper }}$ is the upper limit in the loading protocol, and $P_{\text {lower }}$ is the lower limit in the loading protocol; $f$ is the deformation of the specimens when the load varies from lower limit to the upper limit; $l$ is the span length between the two bearings; $b$ and $h$ are the actually measured cross sectional dimensions of the specimens. The average bending modulus is obtained as $22,310 \mathrm{MPa}$ with a variation coefficient of $9.4 \%$.

\section{Discussions}

The main mechanical parameters obtained from the experiments are given in Table 1. In the longitudinal direction, it can be found that the tensile strength is almost identical to the compressive strength, while the compressive stiffness is almost $50 \%$ larger than the stiffness in tension. In the radial direction, the compressive strength is eight times larger than the tensile strength. In the tangential direction, the compressive strength is five times larger than the tensile strength. Both for compression and tension tests, the parallel-to-grain strength values are much larger than the perpendicular-to-grain strength values. Furthermore, the compressive stiffness parallel to the grain is almost eleven times higher than the compressive stiffness perpendicular to the grain. 
Fig. 15 Test setup of static bending modulus test
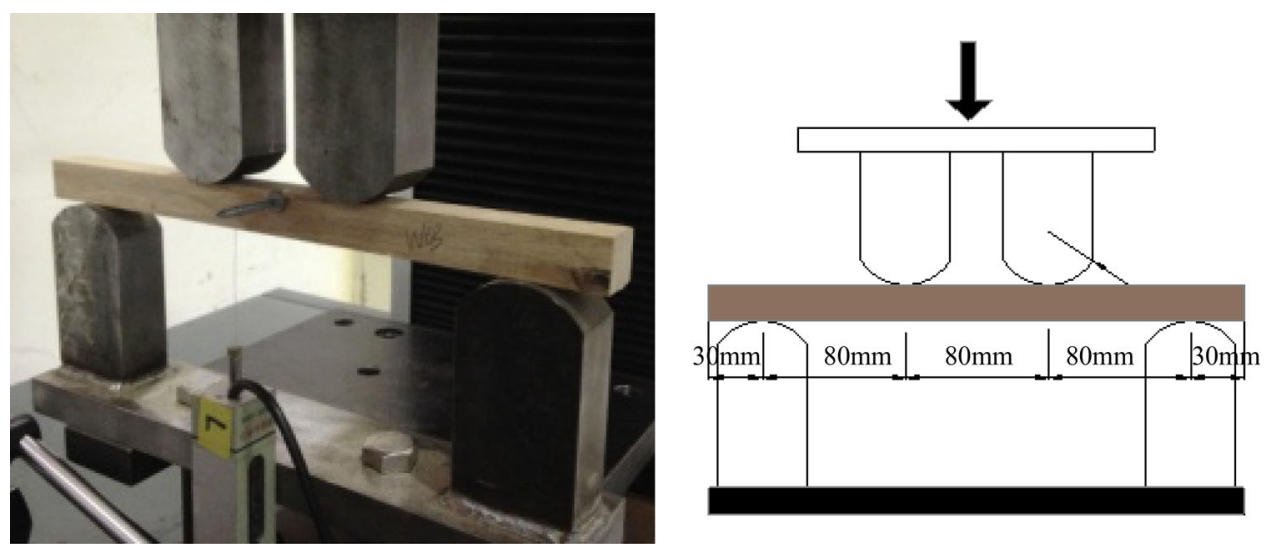

Table 2 Mechanical properties for the scrimber and comparable timber/bamboo-based materials

\begin{tabular}{|c|c|c|c|c|c|c|c|c|c|}
\hline \multirow[t]{2}{*}{ Products/specie } & \multirow{2}{*}{$\begin{array}{l}\text { Density } \\
\rho \\
\mathrm{kg} / \mathrm{m}^{3}\end{array}$} & \multicolumn{2}{|c|}{ Compression } & \multicolumn{2}{|c|}{ Tension } & \multirow{2}{*}{$\begin{array}{l}\text { Shear } \\
f_{\|}^{\mathrm{s}} \\
\mathrm{MPa}\end{array}$} & \multicolumn{2}{|c|}{ Flexural } & \multirow{2}{*}{$\begin{array}{l}f^{\mathrm{b}} / \rho \\
10^{4} \mathrm{~m}^{2} \mathrm{~s}^{-2}\end{array}$} \\
\hline & & $\begin{array}{l}f_{\|}^{\mathrm{c}} \\
\mathrm{MPa}\end{array}$ & $\begin{array}{l}f_{\perp}^{\mathrm{c}} \\
\mathrm{MPa}\end{array}$ & $\begin{array}{l}f_{\|}^{\mathrm{t}} \\
\mathrm{MPa}\end{array}$ & $\begin{array}{l}f_{\perp}^{\mathrm{t}} \\
\mathrm{MPa}\end{array}$ & & $\begin{array}{l}f^{\mathrm{b}} \\
\mathrm{MPa}\end{array}$ & $\begin{array}{l}E^{\mathrm{b}} \\
\mathrm{MPa}\end{array}$ & \\
\hline Scrimber & 885 & 101 & 21 & 108 & 3.4 & 17 & 140 & 22,310 & 15.8 \\
\hline Sitka spruce [28] & 383 & 36 & - & 59 & - & 9 & 67 & 8000 & 17.5 \\
\hline SPF glulam [29] & 408 & 28 & 4 & - & 1.2 & 3.5 & 32 & 12,175 & 7.8 \\
\hline Douglas-fir LVL [30] & 520 & 57 & - & 49 & - & 11 & 68 & 13,000 & 13.1 \\
\hline Glubam [31] & $800-980$ & 51 & - & 82 & - & - & 99 & 10,400 & $10.1-12.4$ \\
\hline Glulam Guadua [32] & 741 & 62 & - & 143 & 3.2 & 9.5 & 122.4 & 13,260 & 16.5 \\
\hline
\end{tabular}

$L V L$ laminated veneer lumber

Comparisons of mechanical parameters of the scrimber composite with Sitka spruce [28], Spruce-pine-fir (SPF) glulam [29], Douglas-fir LVL [30], glubam [31] and glulam Guadua [32] are shown in Table 2. In the parallel-tograin direction, it is noted that compressive strength of the scrimber is significantly larger than the other five species or products. The tensile strength of the scrimber is almost $25 \%$ lower than that of glulam Guadua, but it is larger than the other species or products. In the perpendicular-to-grain direction, it can be observed that compressive strength of the scrimber is four times larger than the compressive strength of SPF glulam. The tensile strength of the scrimber is almost identical to that of glulam Guadua, but is much larger than that of SPF glulam. Shear strength of the scrimber also far surpasses the other species or products, and it is almost five times the shear strength of SPF glulam. Table 2 also gives the flexural strength and flexural modulus values. The flexural strength of the scrimber is $14 \%$ larger than that of glulam Guadua, and is up to three times higher than that of SPF glulam. The scrimber also has a considerably larger modulus of elasticity (MOE) value than the other five species or products, up to almost twice larger than that of Sitka spruce. Its flexural strength to density
Table 3 Selected mechanical properties for the scrimber and comparable poplar-based materials

\begin{tabular}{lllr}
\hline Products/specie & $\begin{array}{l}\text { Density } \\
\mathrm{kg} / \mathrm{m}^{3}\end{array}$ & $\begin{array}{l}\text { Flexural } \\
\text { strength } \\
\mathrm{MPa}\end{array}$ & $\begin{array}{l}\text { MOE } \\
\mathrm{MPa}\end{array}$ \\
\hline Scrimber & 885 & 140 & 22,310 \\
Solid poplar [9] & 400 & 69 & 6127 \\
Poplar OSB [33] & 630 & 63 & 8301 \\
Poplar LVL [9] & 438 & 84 & 6819 \\
Hybrid poplar LVL [34] & 490 & 96 & 8364 \\
\hline
\end{tabular}

$M O E$ modulus of elasticity, $O S B$ oriented strand board, $L V L$ laminated veneer lumber

ratio is slightly lower than those of Sitka spruce and glulam Guadua, but is larger than those of the other three products.

Comparisons of selected mechanical parameters of the scrimber composite with those of solid poplar and other poplar-based products are also conducted. Static flexural strength and MOE values of solid poplar [9], poplar oriented strand board (OSB) [33], poplar LVL [9] and hybrid poplar LVL [34] are shown in Table 3. It can be found that the flexural strength of the scrimber is approximately 
twice the value of solid poplar or poplar OSB, and is about $50 \%$ larger than the flexural strength values of the two types of LVL. Moreover, the scrimber has a considerably larger MOE than solid poplar and the other three poplar products.

It is noted that the scrimber composite has larger strength values in almost all mechanical properties. The increased capacity is attributed to the confinement of fibers. With desirable strength and MOE values, the scrimber composite is able to serve as a promising alternative for existing wood/bamboo-based composite materials in building constructions. Furthermore, utilization of fastgrowing wood for manufacturing scrimber composite is quite beneficial to the natural forests and building industries due to its low price and sustainability.

\section{Conclusions}

This paper presents the production and mechanical properties of a scrimber composite manufactured from poplar wood. Various experiments were conducted to determine mechanical parameters of the scrimber. Furthermore, comparisons of mechanical properties of the scrimber with those of other types of timber/bamboobased materials were presented. According to the test results and comparisons, the main conclusions can be summarized as follows,

1. The scrimber composite is produced through mechanical slicing, drying, thermal treatment, impregnation, cold molding and hot curing. The cross section of the scrimber composite is featured by curved thin laminates, which is quite different from existing veneerbased laminated products.

2. Results from the tests indicate that the stiffness and strength properties of the scrimber composite are dramatically affected by grain directionality.

3. Comparisons of mechanical parameters of the scrimber with those of other timber/bamboo-based products indicate that with high strength and MOE values, the scrimber can be used as a feasible construction material. Such scrimber is suitable to serve as a good substitute for wood/bamboo-based composite materials in building constructions.

4. To evaluate the behavior of structural components made of such scrimber, experimental and numerical studies on the mechanical behavior of full-scale scrimber members or assemblies are still needed to further provide technical bases for their structural applications in practical engineering.

\section{References}

1. Maloney TM (1993) Modern particleboard and dry-process fiberboard manufacturing. Miller Freeman Inc, São Francisco

2. Chen TY (1990) The suitability of structural particleboard made from fast-growing tree species. Holz Roh Werkst 48:467-471

3. Hegazy SS, Aref IM (2010) Suitability of some fast-growing trees and date palm fronds for particleboard production. For Prod J 60:599-604

4. Kalaycioglu H, Deniz I, Hiziroglu S (2005) Some of the properties of particleboard made from paulownia. J Wood Sci $51: 410-414$

5. Trianoski R, Iwakiri S, De Matos JLM (2011) Potential use of planted fast-growing species for production of particleboard. J Trop For Sci 23:311-317

6. Çolak S, Aydin İ, Demirkir C, Çolakoğlu G (2004) Some technological properties of laminated veneer lumber manufactured from pine (Pinus sylvestris L.) Veneers with Melamine AddedUF Resins. Turk J Agric For 28:109-113

7. Harding OV, Orange RP (1998) The effect of juvenile wood and lay-up practices on various properties of radiata pine laminated veneer lumber. For Prod J 48:63-70

8. Aydin I, Çolak S, Çolakoğlu G, Salih E (2004) A comparative study on some physical and mechanical properties of Laminated Veneer Lumber (LVL) produced from Beech (Fagus orientalis Lipsky) and Eucalyptus (Eucalyptus camaldulensis Dehn.) veneers. Holz Roh Werkst 62:218-220

9. Burdurlu E, Kilic M, Ilce AC, Uzunkavak O (2007) The effects of ply organization and loading direction on bending strength and modulus of elasticity in laminated veneer lumber (LVL) obtained from beech (Fagus orientalis L.) and lombardy poplar (Populus nigra L.). Constr Build Mater 21:1720-1725

10. Shukla SR, Kamdem DP (2009) Properties of laboratory made yellow poplar (Liriodendron tulipifera) laminated veneer lumber: effect of the adhesives. Eur J Wood Wood Prod 67:397-405

11. Tenorio C, Moya R, Muñoz F (2011) Comparative study on physical and mechanical properties of laminated veneer lumber and plywood panels made of wood from fast-growing Gmelina arborea trees. J Wood Sci 57:134-139

12. Moya R, Tenorio C, Carranza M, Camacho D, Quesada-Pineda H (2013) Structural performance of I-beam fabricated from a fastgrowing tree, gmelina arborea. J Trop For Sci 25:206-212

13. Herawati E, Massijaya MY, Nugroho N (2010) Performance of glued-laminated beams made from small diameter fast-growing tree species. J Biol Sci 10:37-42

14. Kim YJ, Okuma M, Yokota T (1998) Study on sheet material made from zephyr strands $\mathrm{V}$ : properties of zephyr strand board and zephyr strand lumber using the veneer of fast-growing species such as poplar. J Wood Sci 44:438-443

15. Yildiz UC, Yildiz S, Gezer ED (2005) Mechanical properties and decay resistance of wood-polymer composites prepared from fast growing species in Turkey. Bioresour Technol 96:1003-1011

16. Ding WD, Koubaa A, Chaala A (2013) Mechanical properties of MMA-hardened hybrid poplar wood. Ind Crop Prod 46:304-310

17. Sheriff DW (1998) Productivity and economic assessment of hardwood species for scrimber production. RIRDC Publication, No 98/4 January

18. Yu YL, Zhu RX, Wu BL, Hu YA, Yu WJ (2015) Fabrication, material properties, and application of bamboo scrimber. Wood Sci Technol 49:83-98

19. Yu HX, Fang CR, Xu MP, Guo FY, Yu WJ (2014) Effects of density and resin content on the physical and mechanical properties of scrimber manufactured from mulberry branches. J Wood Sci 61:159-164 
20. Wei PX, Wang BJ, Zhou DG, Dai CP, Wang QZ, Huang SW (2013) Mechanical properties of poplar laminated veneer lumber modified by carbon fiber reinforced polymer. BioResources 8:4883-4898

21. GB/T 1935-2009 (2009) Method of testing in compressive strength parallel to grain of wood. China' National Standard, Beijing

22. GB/T 1939-2009 (2009) Method of testing in compression perpendicular to grain of wood. China' National Standard, Beijing

23. GB/T 1938-2009 (2009) Method of testing in tensile strength parallel to grain of wood. China' National Standard, Beijing

24. ASTM D143-14 (2014) Standard test method for small clear specimen of timber. American Society for Testing Material Standard, West Conshohocken

25. GB/T 1937-2009 (2009) Method of testing in shearing strength parallel to grain of wood. China' National Standard, Beijing

26. GB/T 1936.1-2009 (2009) Method of testing in bending strength of wood. China' National Standard, Beijing

27. GB/T 1936.2-2009 (2009) Method for determination of the modulus of elasticity in static bending of wood. China' National Standard, Beijing

28. Kretschmann DE (2010) Wood handbook Chapter 5: Mechanical properties of wood. Forest Products Laboratory, Department of Agriculture Forest Service, Madison, Wisconsin, USA
29. Liu HF, He MJ (2015) Effects of self-tapping screw on performance of glulam beam-to-column connections. J Build Struct 36:148-156

30. Clouston P, Lam F, Barrett JD (1998) Incorporating size effects in the Tsai-Wu strength theory for Douglas-fir laminated veneer. Wood Sci Technol 32:215-226

31. Xiao Y, Yang RZ, Shan B (2013) Production, environmental impact and mechanical properties of glubam. Constr Build Mater 44:765-773

32. Correal JF, Echeverry JS, Ramírez F, Yamín LE (2014) Experimental evaluation of physical and mechanical properties of glued laminated Guadua angustifolia Kunth. Constr Build Mater 73:105-112

33. Akrami A, Fruehwald A, Barbu MC (2014) The effect of fine strands in core layer on physical and mechanical properties of oriented strand boards (OSB) made of beech (Fagus sylvatica) and poplar (Populus tremula). Eur J Wood Wood Prod 72:521-525

34. Kurt R, Meric H, Aslan K (2012) Laminated veneer lumber (LVL) manufacturing using three hybrid poplar clones. Turk $\mathrm{J}$ Agric For 36:237-245 